\title{
WORKSHOP PENULISAN JURNAL ILMIAH DAN TATA CARA MEMPUBLIKASIKANNYA MELALUI JURNAL ONLINE PADA MAHASISWA FAKULTAS ILMU BUDAYA UNIVERSITAS JAMBI
}

\author{
Rengki Afria', Warni ${ }^{2}$ \\ Universitas Jambi, Indonesia ${ }^{I}$ \\ ;Email: rengkiafria@gmail.com \\ Universitas Jambi, Indonesia ${ }^{2}$ \\ Email:warnii@unja.ac.id
}

\begin{abstract}
Abstrak
Tujuan kegiatan Workshop Penulisan Jurnal Ilmiah dan tata cara mempublikasikannya melalui jurnal online pada mahasiswa Fakultas Ilmu Budaya Universitas Jambi adalah untuk memberikan pengetahuan bagi mahasiswa yang belum berpengalaman dalam menulis artikel ilmiah di jurnal online, khususnya bagi mahasiswa Fakultas Ilmu Budaya Universitas Jambi. Metode pengabdian masyarakat yang digunakan dalam pengabdian kepada masyarakat ini adalah metode campuran, yakni metode presentasi dan metode praktik. Metode presentasi dilakukan dengan menjelaskan materi jurnal online dan tatacara menggunggah artikel dalam laman jurnal, sedangkan metode praktik dilakukan dengan mempraktikkan cara menggunggah artikel ilmiah ke dalam OJS. Adapun langkah-langkah yang digunakan adalah mulai dari perencanaan, pengorganisasian, pelaksanaan, dan evaluasi. Berdasarkan workshop yang telah dilaksanakan, maka dapat disimpulkan bahwa kegiatan ini telah berjalan dengan baik dan lancar. Dengan demikian, dapat dikatakan bahwa kegiatan Workshop Penulisan Jurnal Ilmiah dan tata cara mempublikasikannya melalui jurnal online pada mahasiswa Fakultas Ilmu Budaya Universitas Jambi dapat meningkatkan kemampuan mahasiswa dalam membuat jurnal ilmiah dan mempublikasikannya di dalam OJS.
\end{abstract}

Kata Kunci: Workshop, Penulisan, Publikasi, Jurnal, Online.

\section{Abstract}

The purpose of the Scientific Journal Writing Workshop and the procedure for publishing it through online journals for students of the Faculty of Cultural Sciences, Jambi University is to provide knowledge for students who are not experienced in writing scientific articles in online journals, especially for students of the Faculty of Cultural Sciences, Jambi University. Community service methodsmixed methods used in this community service, namely methods of presentation and methods of practice. The presentation method is carried out by explaining the online journal material and the procedure for uploading articles on the journal page, while the practical method is carried out by practicing how to upload scientific articles into OJS. The steps used are starting from planning, organizing, implementing, and evaluating. Based on the workshops that have been carried out, it can be concluded that this activity has gone well and smoothly. Thus, it can be said that the Scientific Journal Writing Workshop activities and procedures for publishing them through online journals for students of the Faculty of Cultural Sciences, Jambi University can improve students' abilities to make scientific journals and publish them in OJS.

Keywords: Workshop, Writing, Journal, Publication, Online 


\section{PENDAHULUAN}

Usaha untuk mewujudkan Universitas Jambi menjadi Universitas Kelas Dunia (world class university) memang tidak mudah. Kelemahan utama lebih disebabkan oleh motivasi dosen dan mahasiswa untuk meneliti hanya dikaitkan dengan usaha kenaikan pangkat kepegawaian dan syarat kelulusan saja. Civitas akademika Universitas Jambi merupakan sumber daya yang dituntut untuk memiliki kemampuan yang lebih dari masyarakat biasa karena kapasitasnya yang lebih intens berinteraksi dengan ilmu pengetahuan. Hal tersebut sudah sepatutnya mampu mengaktualisasikan kompetensinya bukan sekedar kegiatan penelitian, tetapi mampu untuk menulis hasil penelitian tersebut dalam media publikasi baik yang bertaraf nasional, regional, maupun internasional. Yang pada akhirnya dapat berkontribusi positif bagi permasalahan dan kesejahteraan bangsa. Publikasi tersebut berupa jurnal ilmiah. Karya ilmiah adalah suatu tulisan yang memuat kajian suatu masalah tertentu dengan menggunakan kaidah-kaidah keilmuan. Kaidah-kaidah keilmuan itu mencakup penggunaan metode ilmiah dan pemenuhan prinsip-prinsip keilmiahan, seperti: objektif, logis, empiris, sistematis, lugas, jelas, dan konsisten (Budiyanto, 2008).

Jurnal ilmiah merupakan jurnal akademik yang ditulis oleh peneliti yang bersumber dari penelitian ilmiah. Dalam bahasa Inggris, jurnal diterjemahkan sebagai 'scientific journal' atau 'academic journal'. Jurnal akademik dapat dideskripsikan sebagai tulisan ilmiah yang dipublikasikan secara reguler dalam rangka mendiseminasi hasil penelitian. Hasil penelitian yang didiseminasikan sering kali menantang asumsi umum yang beredar di kalangan publik atau menantang (kritik) temuan penelitian sebelumnya. Bisa pula hasil diseminasi menampilkan data baru dalam literatur akademik (Suprayitno, 2019). Lebih lanjut, Wening, dkk (2009) mengemukakan bahwa Karya Tulis Ilmiah adalah laporan tertulis tentang (hasil) kegiatan ilmiah. Karena kegiatan ilmiah itu banyak macamnya, maka laporan kegiatan ilmiah juga beragam bentuknya.

Penulisan jurnal bersifat spesifik yang ditulis dalam perspektif disiplin atau subdisiplin ilmu tertentu. Dalam artian, merepresentasikan spesialisasi bidang ilmu pengetahuan tertentu yang akhirnya terpublikasi. Publikasi ilmiah ini sebagai bukti hasil riset yang diarahkan untuk melahirkan inovasi demi mendongkrak daya saing bangsa. Sebagai sarana pengembangan ilmu pengetahuan, jurnal ilmiah merupakan arena diskursus intelektual melalui tulisan. Pengembangan ilmu pengetahuan dapat dilakukan dengan temuan penelitian, kritik terhadap temuan penelitian, pembentukan konsensus dan temuan baru. Proses tersebut berlangsung terus-menerus. Begitulah ilmu pengetahuan berkembang dan jurnal berperan penting sebagai sarananya.

Perguruan tinggi di Indonesia mewajibkan penulisan jurnal ilmiah dan dipublikasikan melalui jurnal online. Hal tersebut berdasarkan peraturan Kementerian Pendidikan bahwa setiap mahasiswa yang akan lulus pada program sarjana (S-1) wajib untuk menulis karya ilmiah yang disebut dengan skripsi. Peraturan ini tertuang dalam Surat Edaran Kementerian Pendidikan yang dituangkan dalam Surat Edaran No. 
152/E/T/2012 bahwa semua mahasiswa yang akan lulus $S_{1}, S_{2}$, dan $S_{3}$ wajib mempublikasikan karya tulisnya di jurnal ilmiah. Hal ini tentu tidak terkecuali untuk Fakultas Ilmu Budaya Universitas Jambi. Hal tersebut menunjukkan bahwa penulisan jurnal ilmiah ini merupakan ketentuan perguruan tinggi tertentu sebagai salahsatu sistem dalam mengevaluasi hasil studi mahasiswa yang telah menyelesaikan seluruh mata kuliah dengan program akademis.

Oleh karena itu, untuk meningkatkan jumlah publikasi dan mutu penelitian ilmiah yang dipublikasikan di jurnal online (OJS), maka diperlukan pengetahuan untuk menulis jurnal ilmiah. Dengan itulah Tim Pengabdian Kepada Masyarakat (PPM) bekerjasama dengan Unit Fakultas Ilmu Budaya Universitas Jambi melaksanakan Workshop Penulisan Jurnal Ilmiah dan tata cara mempublikasikannya melalui jurnal online pada mahasiswa Fakultas Ilmu Budaya Universitas Jambi.

Pembuatan karya tulis ilmiah berupa jurnal ini, nampaknya banyak sekali kendala yang dihadapi oleh mahasiswa. Adapun kendalanya adalah mahasiswa belum mempunyai pengetahuan untuk membuat jurnal ilmiah dan juga mahasiswa tidak menguasai teknologi online untuk mengunggah atau mempublikasikan hasil penelitian ilmiahnya melalui jurnal online. Penerbitan jurnal ilmiah dalam tatacara publikasinya memerlukan platform yang mendukung penerbitan jurnal ilmiah secara daring, yakni OJS (Busro, dkk., 2018).

Permasalahan lainnya adalah dalam Fakultas Ilmu Budaya Universitas Jambi belum membuat regulasi tentang penulisan jurnal ilmiah yang dipublikasikan pada jurnal onlne sebagai sebuah syarat kelulusan. Untuk itu perlu dibuat regulasi agar mahasiswa aktif dalam menulis jurnal ilmiah dan mempublikasikannya dalam jurnal online (OJS). Dengan adanya hal tersebut, maka secara tidak langsung dapat meningkatkan penguatan literasi teknologi bagi mahasiswa (Warni dan Afria, 2020).

Sebagai dasar pijakan hal tersebut, maka perlu adanya sebuat workshop penulisan jurnal ilmiah agar mahasiswa mempunya pengetahuan dalam membuat artikel ilmiah berupa jurnal dan mempublikasikannya. Berdasarkan konsepsi di atas, maka pada workshop ini memfokuskan masalah pada penulisan jurnal dan publikasinya sehingga mahasiswa memiliki kompetensi untuk menuangkan gagasan-gagasan dalam bentuk tulisan ilmiah dalam rangka mendukung nalar kritis secara akademik.

Secara umum tujuan kegiatan pengabdian ini adalah dalam rangka mengorganisasi kegiatan pelatihan penulisan artikel ilmiah bagi mahasiswa di lingkungan Fakultas Ilmu Budaya Universitas Jambi, maka tim pengabdian kepada masyarakat mencoba untuk menyatukan kegiatan workshop penulisan jurnal ilmiah dan tata cara mempublikasikannya dalam jurnal online secara terpusat dalam rumpun keilmuwan. Adapun tujuan dari kegiatan ini, yakni (a) Memberikan pengetahuan bagi mahasiswa yang belum berpengalaman dalam menulis artikel ilmiah di jurnal online, khususnya bagi mahasiswa Fakultas Ilmu Budaya Universitas Jambi yang akan melakukan penelitian tugas akhir (skripsi), (b) Mengembangkan pengetahuan dan meningkatkan kualitas penulisan jurnal ilmiah bagi mahasiswa Fakultas Ilmu Budaya 
Universitas Jambi, (c) Mendorong dan meningkatkan jumlah publikasi hasil riset para mahasiswa Fakultas Ilmu Budaya Universitas Jambi. Oleh karena itu manfaat yang hendak dicapai setelah kegiatan pelatihan adalah meningkatnya pemahaman dan kemampuan mahasiswa tentang (a) Dasar-dasar penulisan karya tulis ilmiah (jurnal) untuk rumpun ilmu ilmu sosial humaniora, (b) Hal-hal yang perlu dan tidak perlu dilakukan dalam penulisan jurnal ilmiah, (c) Penulisan jurnal ilmiah dalam bahasa yang baku, yang baik dan benar, serta sesuai dengan tata gramatikal untuk bidang ilmu sosial humaniora, (d) Tata cara mengunggah jurnal ilmiah ke jurnal online dimulai dari register sampai submission, (d) Penyusunan dan perbaikan proposal artikel ilmiah oleh masing-masing peserta yang akan dikirim ke jurnal online.

\section{METODE}

Metode yang digunakan dalam pengabdian kepada masyarakat ini adalah metode campuran. Metode tersebut menggunakan metode presentasi dan metode praktik (Putra, 2019; Febrillia, dkk, 2020). Metode presentasi dilakukan dengan menjelaskan materi jurnal online dan tatacara menggunggah artikel dalam laman jurnal, sedangkan metode praktik dilakukan dengan mempraktikkan cara menggunggah artikel ilmiah ke dalam OJS. Pengabdian ini dilakukan dengan menempuh langkah-langkah sebagai berikut:

\section{Gambar 1. Bagan Alir Pengabdian}

1. Perencanaan; menyusun program pengabdian, memilih sasaran, dan pematangan konsep workshop.

2. Pengoraganisasian; mengatur waktu dan tempat pelaksanaan pengabdian dan persiapan materi.

3. Pelaksanaan; memberikan materi, praktik penulisan dan tatacara publikasi, publikasi (Sumartini, 2019; Hidayat, 2020).

4. Evaluasi; mereview tulisan dan mengukur tingkat kematangan dalam menulis, dan mampu menguasai tata cara publikasi dalam OJS.

\section{HASIL DAN PEMBAHASAN}

Kegiatan Pengabdian Kepada Masyarakat dengan judul "Workshop Penulisan Jurnal Ilmiah dan tata cara mempublikasikannya melalui jurnal online pada mahasiswa Fakultas Ilmu Budaya Universitas Jambi" ini memberikan hasil yang cukup baik seperti

a. Mahasiswa mampu membuat tulisan ilmiah yang sesuai criteria ilmiah.

b. Mahasiswa mampu mengembangkan ide dan konsep berdasarkan teori dalam bentuk tulisan ilmiah.

c. Mahasiswa mempunyai wawasan tentang penulisan artikel ilmiah. 
d. Mahasiswa memperoleh informasi tentang jurnal ilmiah yang dapat menampung artikel mereka.

e. Mahasiswa memiliki pengetahuan dalam tata cara publikasi kedalam OJS

f. Mahasiswa mampu membuat akun untuk mengsubmitkan artikel ilmiahnya ke dalam OJS.

Langkah-langkah membuat akun dan mengsubmisi artikel ke dalam OJS :

1. Ketik kata kunci nama jurnal yang sudah OJS di laman google (Contoh: Titian: Jurnal Ilmu Humaniora, https://online-journal.unja.ac.id/titian/index.php, maka muncul laman OJSnya.

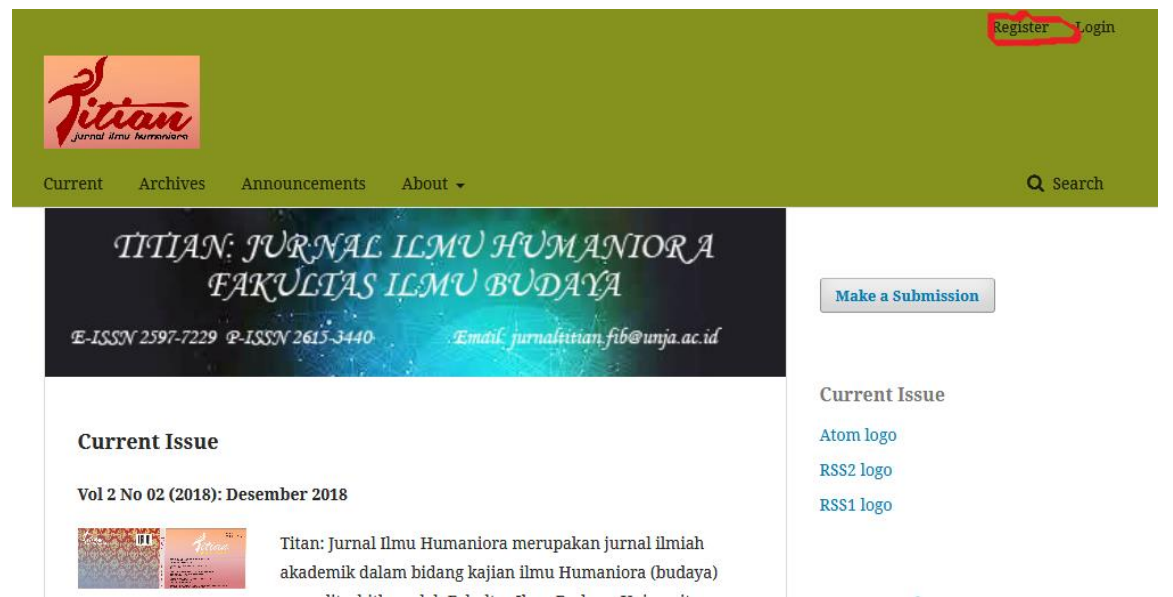

\section{Gambar 2. Laman Jurnal}

2. Setelah laman OJS jurnalnya terbuka maka, anda harus melakukan pendaftaran akun dengan mengklik "register" sehingga laman OJSnya terbuka anda harus mengisi form seperti nama depan, nama tengah (jika ada), nama belakang, afiliasi, dan Negara. Setelah mengisi form tersebut, maka ada diwajibkan untuk mengisi form login anda nantinya di OJS berupa; alamat email aktif, username, dan password (disarankan membuat username dan password yang mudah diingat). Lalu mencontreng polcy statement dan mencontreng CAPCHA (I'am not robot).

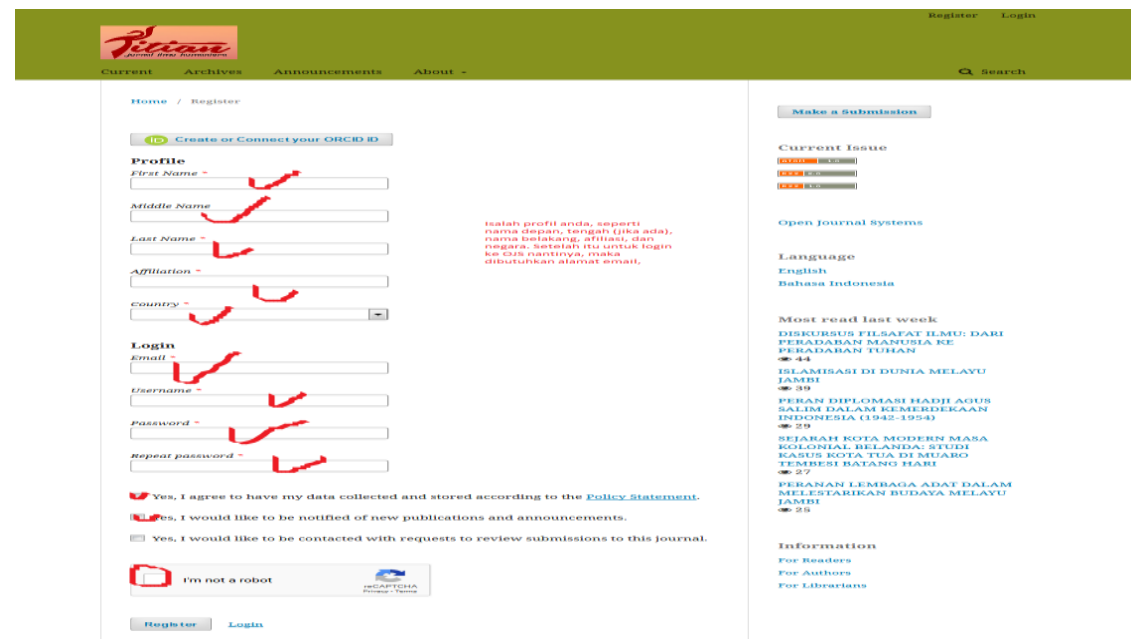

Gambar 3. Pendaftaran Akun Author 
Setelah muncul pilihan capcha, maka pilihlah sesuai perintah, lalu klik "verify"
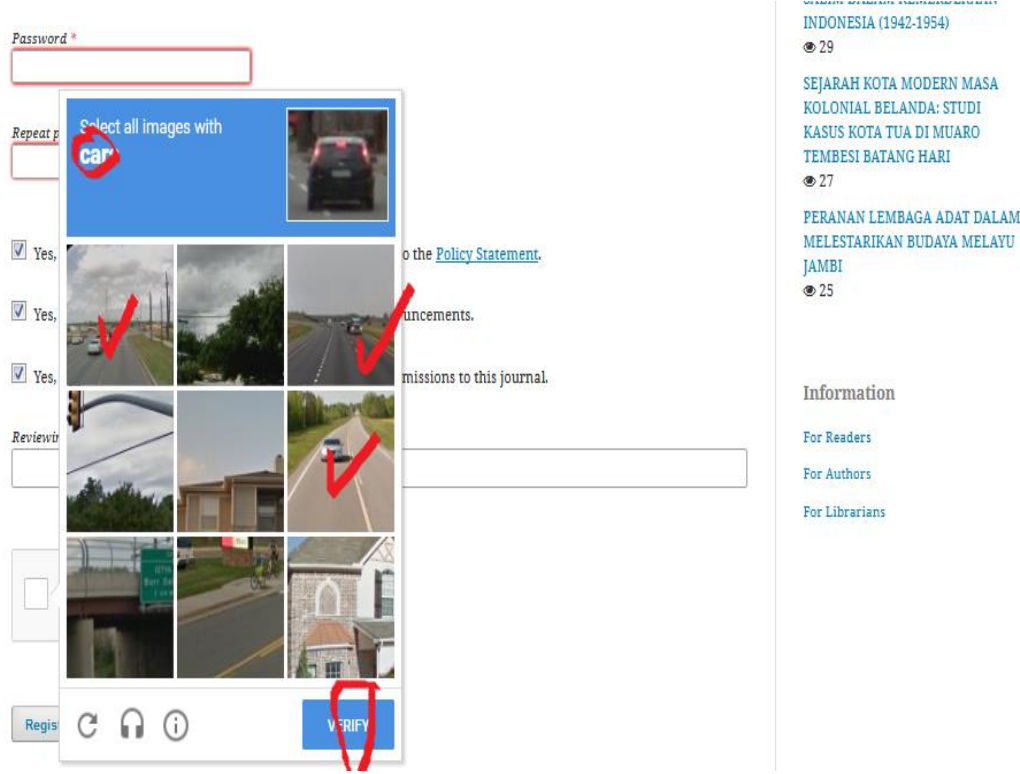

Gambar 5. Verifikasi Akun

Jika kotak box capchanya sudah tercontreng, maka anda harus menekan "register". Setelah itu, akun ada sudah selesai.

3. Biasanya setelah register, secara otomatis anda sudah bisa melakukan submission. Jika tidak, silakan anda login dengan menggunakan username dan pasword yang sudah dibuat.

4. Setelah login pada OJS tahap berikutnya adalah submission.

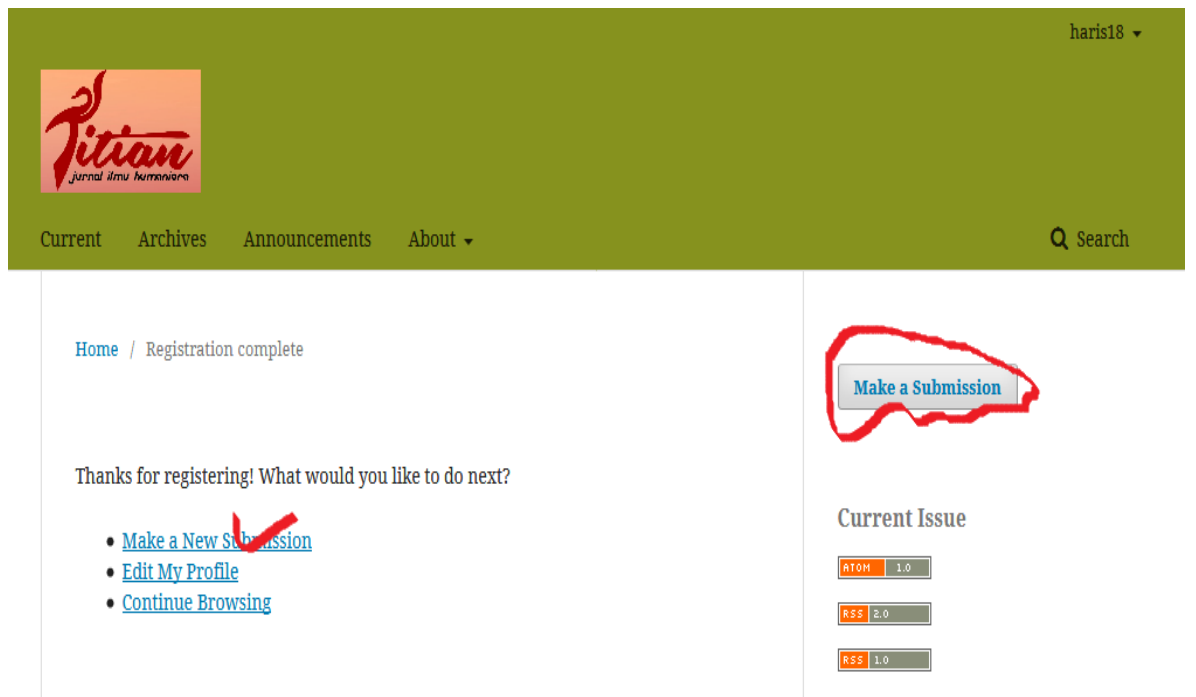

Gambar 6. Tahapan Submisi Artikel

5. Setelah mengklik "make a submission", maka muncul layar submitting. Anda memulai melakukan tahapan submission. Anda harus memilih bahasa, 
E-ISSN: 2776-3331

Vol. 1, No. 1, pp.30-40

Mei 2021

mencontreng semua "submission requirement" kemudian juga mencontreng "corresponding contact" dan jangan lupa klik "save and continue”.

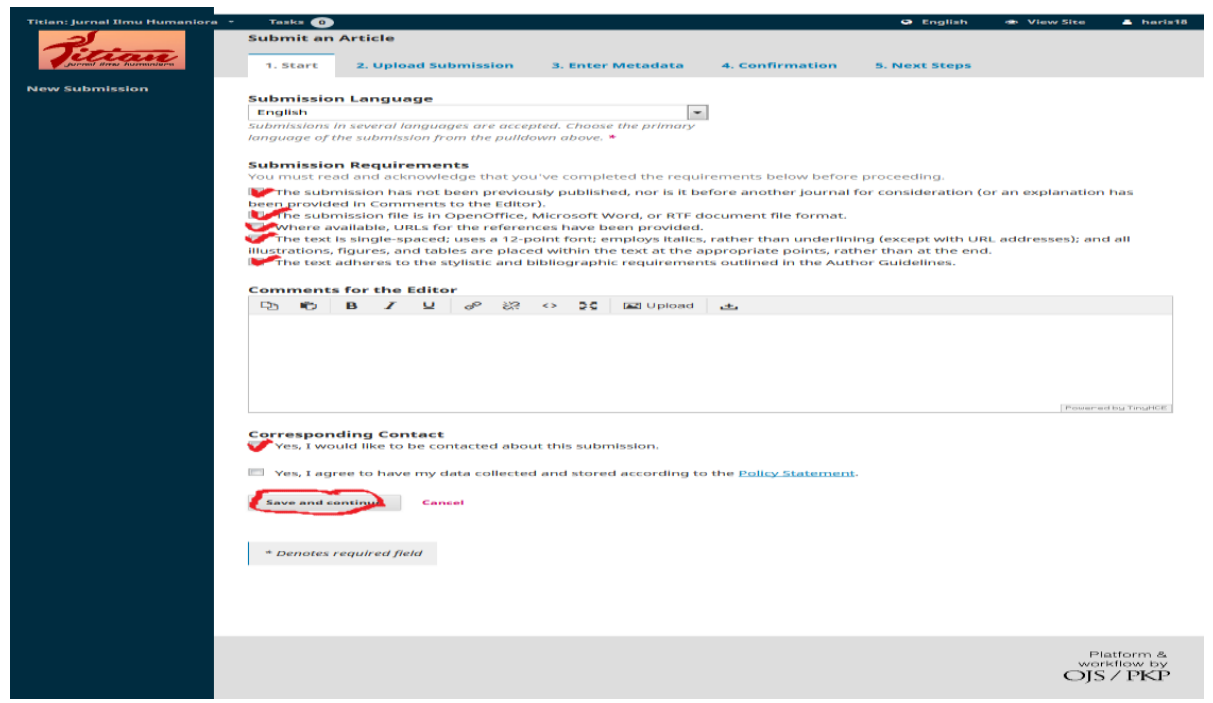

Gambar 7. Laman Submit Artikel

6. Tahap ke dua yakni "upload submission", tahap ini anda mengunggah file artikel anda ke dalam OJS.

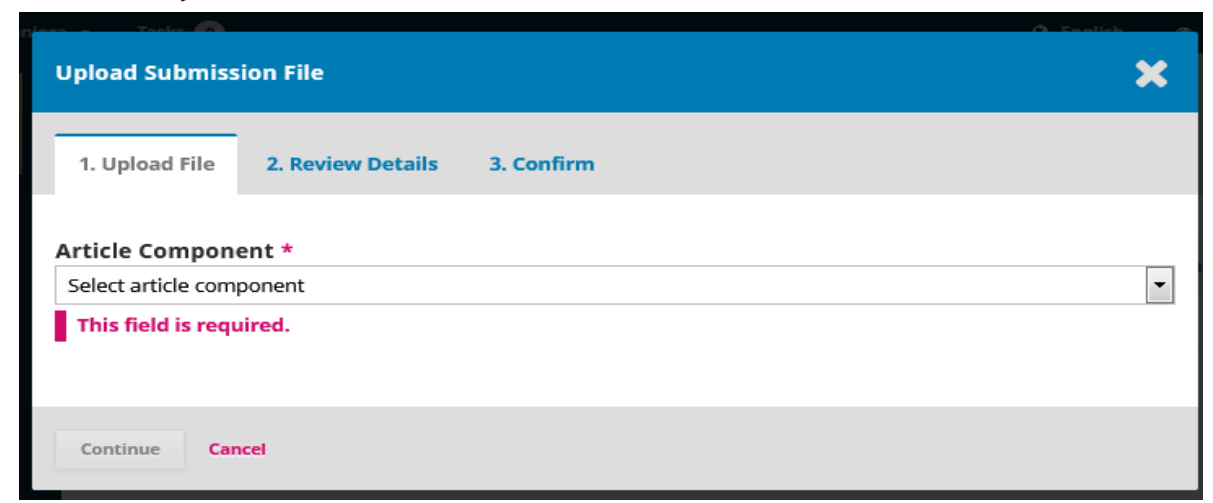

Gambar 8. Mengupload Artikel

Klik artikel komponen anda sebagai "artikel text" lalu secara otomatis muncul menu untuk mendrag atau upload file artikel anda. Setelah file anda ter upload, maka anda harus menekan tombol "continue". (contoh terlampir)

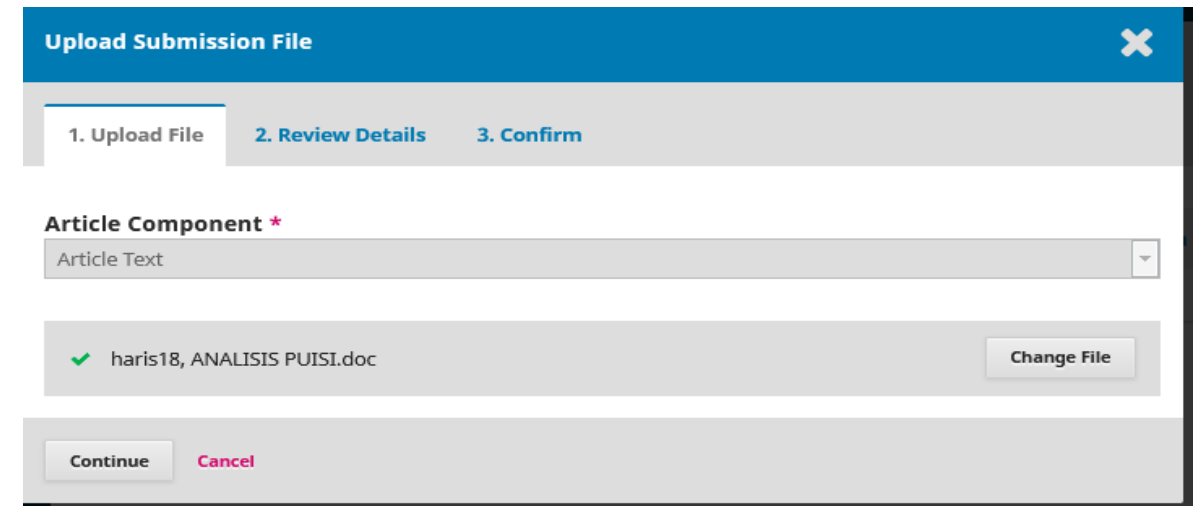

Gambar 9. Mengupload File Artikel 
E-ISSN: 2776-3331

Vol. 1, No. 1, pp.30-40

Mei 2021

Kemudian muncul "review detail” lalu klik "continue"

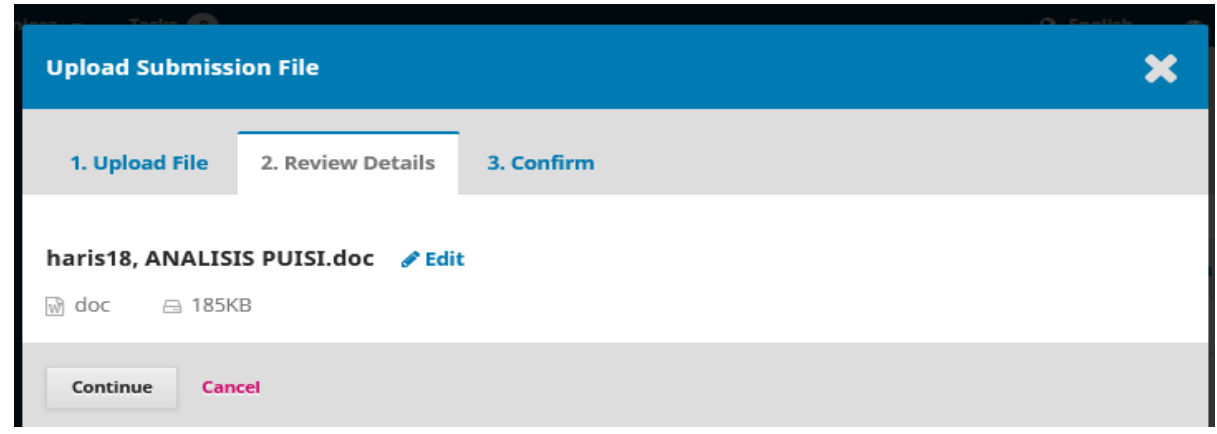

Gambar 10. Tahapan Review Detail Upload Artikel

Kemudian konfirmasi artikel dengan mengklik "complete".

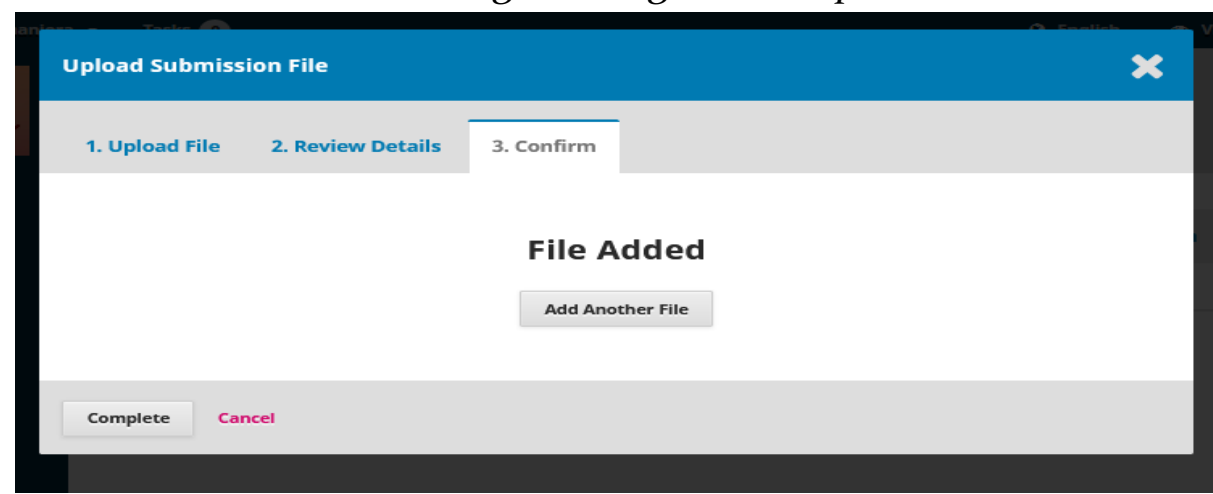

Gambar 11. Konfirmasi Artikel

Dengan ini anda sudah selesai pada tahap upload file artikel dengan menekan "save and continue"

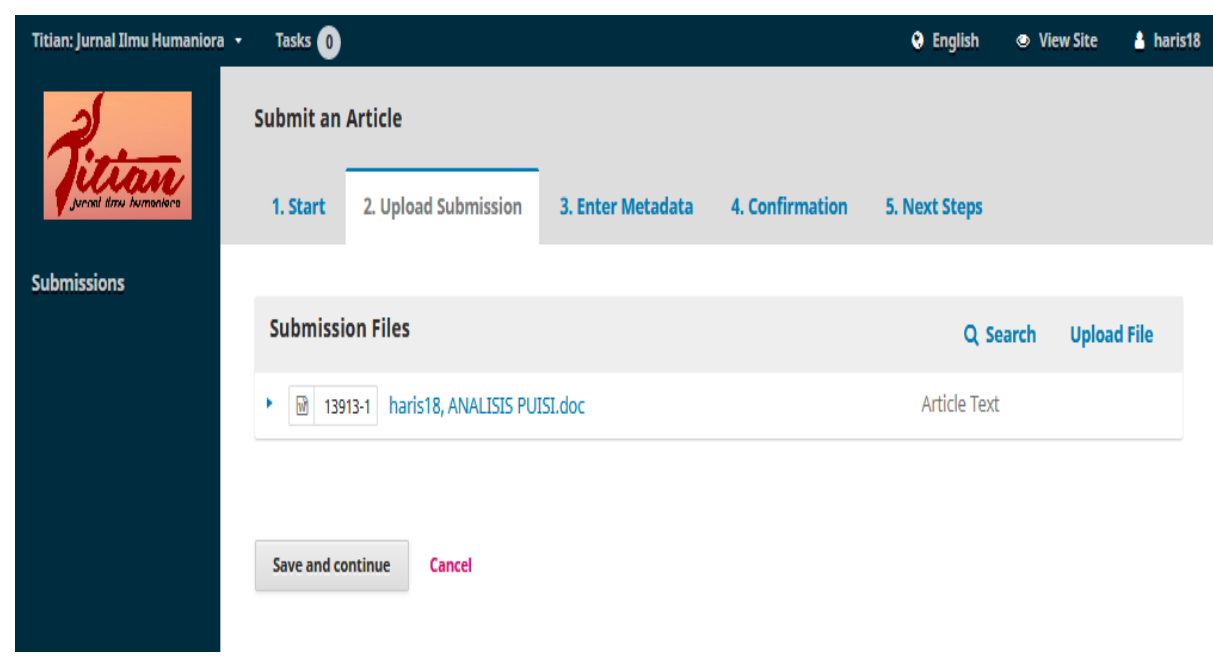

\section{Gambar 12. Menyimpan dan Melanjutkan Artikel yang Terupload}

7. Setelah mengklik save and continue pada tahap di atas maka tahap berikutnya adalah mengisi metadata artikel "enter metadata" untuk mengixi judul, abstrak, author ke-2, tipe teks, disiplin ilmu, kata kunci, dan referensi. Lalu kliklah tombol "save and continue" 


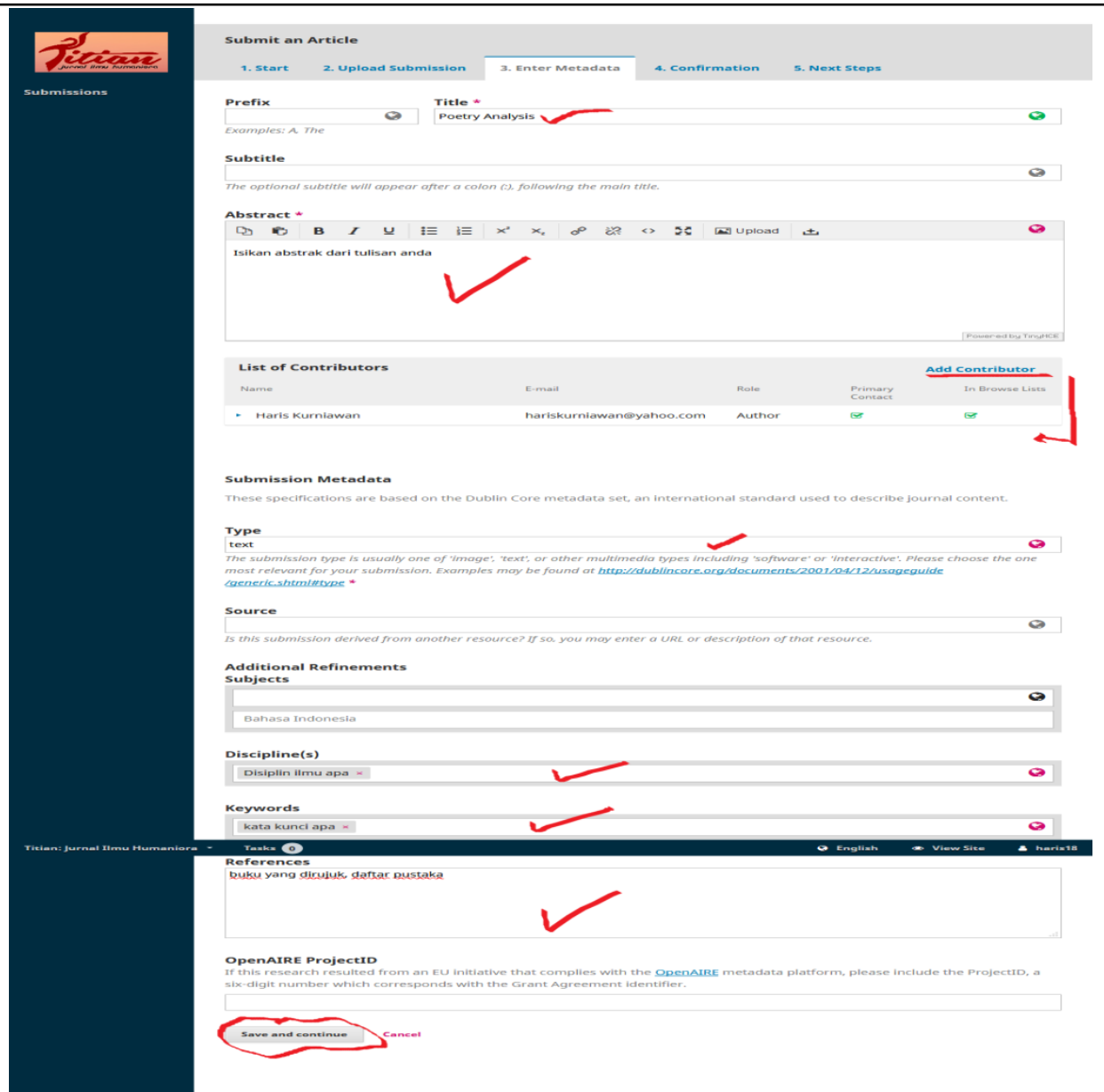

Gambar 13. Mengisi Metadata Artikel

Langkah berikutnya adalah mengkonfirmasi untuk menyelesaikan submission denghan menekan "finish submission" dan tekan ok, maka anda telah melengkapi submissionnya.

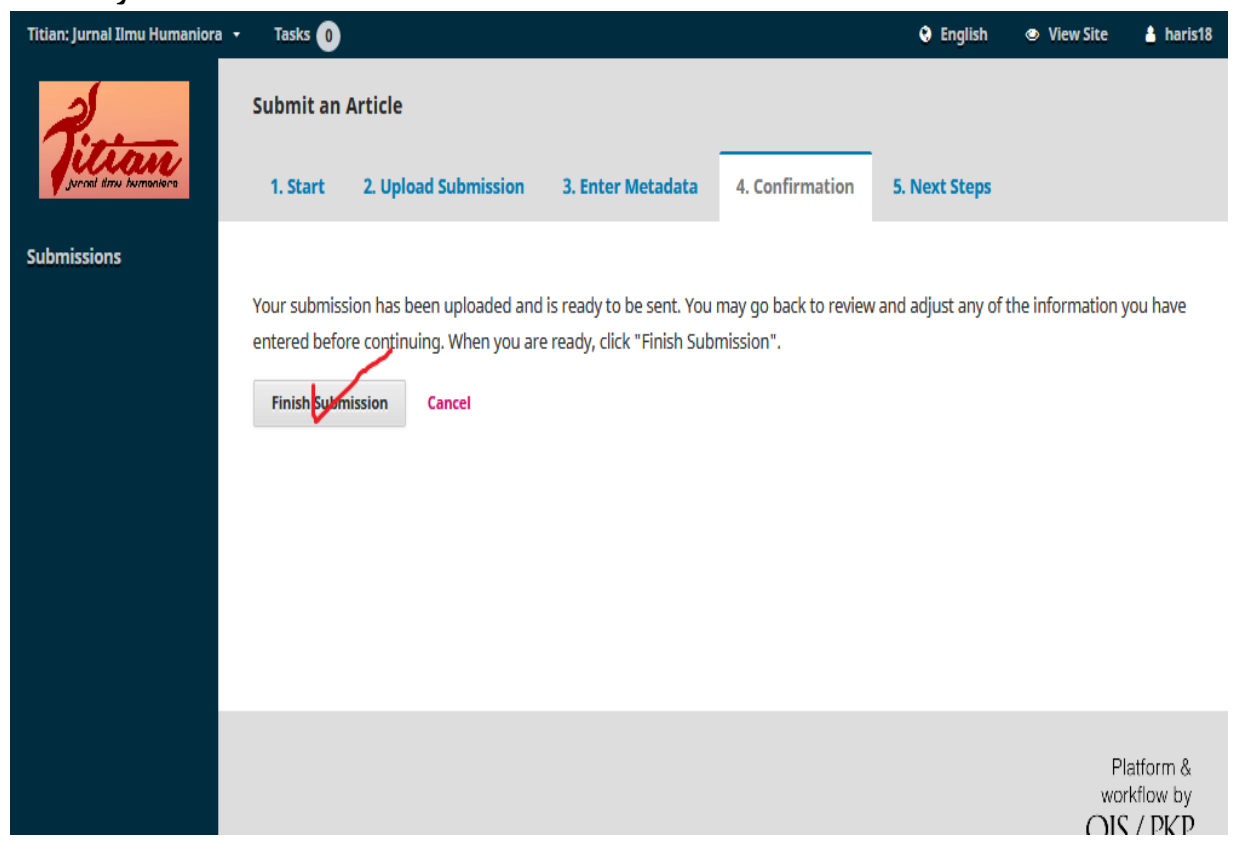

Gambar 14. Konfirmasi Artikel 
8. Setelah melakukan langkah-langkah tersebut, artikel anda sudah tersubmit ke dalam OJS.

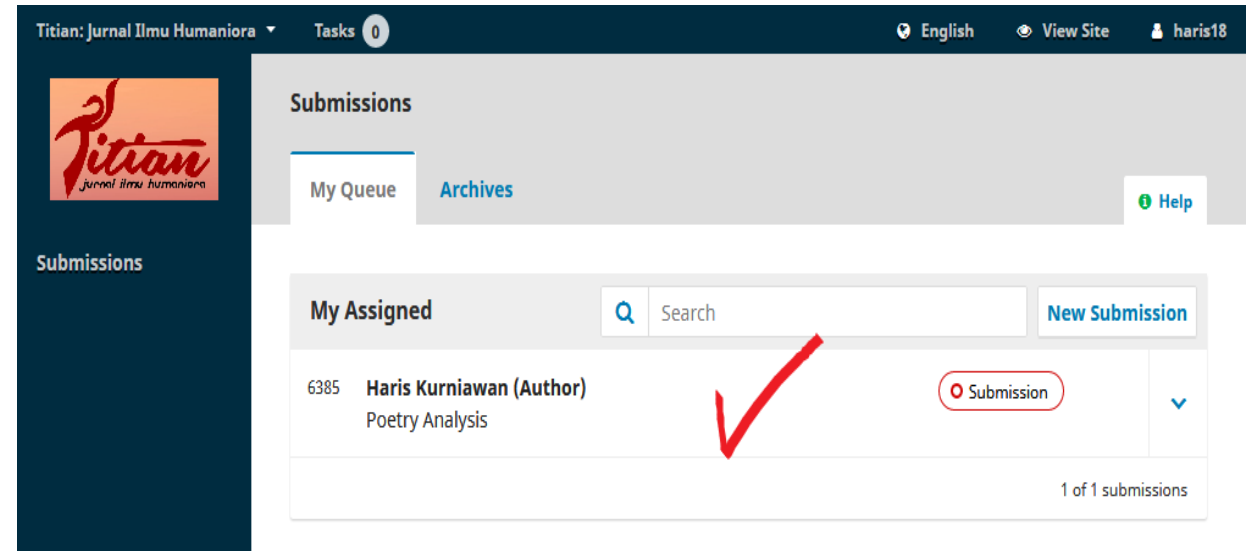

\section{Gambar 15. Artikel Telah Tersubmit}

Luaran pengabdian Workshop Penulisan Jurnal Ilmiah dan tata cara mempublikasikannya melalui jurnal online pada mahasiswa Fakultas Ilmu Budaya Universitas Jambi ini adalah berupa akun OJS dan artikel ilmiah yang telah terpublikasi dalam OJS berupa jurnal.

Berdasarkan kegiatan Workshop Penulisan Jurnal Ilmiah dan tata cara mempublikasikannya melalui jurnal online pada mahasiswa Fakultas Ilmu Budaya Universitas Jambi yang telah dilakukan dapat dilihat bahwa mahasiswa peserta workshop sangat antusias, karena worshop ini merupakan hal yang baru bagi mereka khususnya tatacara publikasi ke OJS. Pengetahuan yang seperti ini memang perlu dilakukan agar mahasiswa berperan aktif dalam menulis ilmiah dan melakukan publikasi.

Sebenarnya banyak mahasiswa yang berpotensi dalam menulis ilmiah, jika didampingi dan memberikan pemahaman dalam menganalisis. Hal ini dibuktikan banyak artikel mahasiswa yang layak untuk dilakukan publikasi, meskipun ada beberapa hal yang harus diperbaiki dalam hasil analisisnya. Setelah dicermati dalam tatacara penulisan, maka perlu dilakukan pendampingan yang intens dalam mengerjakan atau menulis artikel ilmiah sesuai dengan tata cara penulisan jurnal.

\section{KESIMPULAN}

Berdasarkan kegiatan Workshop Penulisan Jurnal Ilmiah dan tata cara mempublikasikannya melalui jurnal online pada mahasiswa Fakultas Ilmu Budaya Universitas Jambi yang telah dilaksanakan, maka dapat disimpulkan bahwa kegiatan ini telah berjalan dengan baik dan lancar. Dengan demikian, dapat dikatakan bahwa kegiatan Workshop Penulisan Jurnal Ilmiah dan tata cara mempublikasikannya melalui jurnal online pada mahasiswa Fakultas Ilmu Budaya Universitas Jambi dapat meningkatkan kemampuan mahasiswa dalam membuat jurnal ilmiah dan mempublikasikannya di dalam OJS. 


\section{REFERENSI}

Budiyanto,

Dwi.

(2008).

Mengenal

Karya

Ilmiah.

http://staffnew.uny.ac.id/upload/132310007/pendidikan/mengenal-karya-ilmiahpengantar-kuliah-pki.pdf

Busro, Ajir Noorseto, Swasti Maharani. (2018). Implementasi Digital Object Indentifier (DOI) pada Website OJS. Yogyakarta: Perkumpulan Relawan Jurnal Indonesia.

Febrillia, BFA., dkk. (2020). Workshop penulisan artikel ilmiah bagi guru MIPA. Jurnal Panrita Abadi, 4(1), 69-76. https://doi.org/10.20956/pa.v4ii.7548

Hidayat, Lukman., Normiyanto, Faiz. (2020). Pelatihan Publikasi Jurnal Hasil Penelitian Tindakan Kelas Bagi Guru SLB N 1 Bantul Yogyakarta. Jurnal Berdaya Mandiri, 2(2), 327-335.

Lembaga Ilmu Pengetahuan Indonesia. (2012). Pedoman Karya Tulis Ilmiah. Jakarta: LIPI

Sumartini, Mulyani, M., Nugroho, B.A. (2019). Workshop Penulisan karya ilmiah bagi guru Sekolah Dasar di Kabupaten Demak. Jurnal Puruhita, 1(1), 54-59.

Suprayitno, Adi. (2019). Pedoman Penyusunan dan Penulisan Jurnal Ilmiah bagi Guru. Yogyakarta: Deepublish.

Surat Edaran Kementrian Pendidikan Nomor 152/E/T/2012 Tahun 2012, tentang Mahasiswa yang Akan Lulus S1, Wajib Mempublikasikan Karya Tulisnya di Jurnal.

Warni, \& Afria, R. (2021). Penguatan Kemampuan Literasi Pada Mahasiswa Fakultas Ilmu Budaya Universitas Jambi. BERNAS: Jurnal Pengabdian Kepada Masyarakat, 2(1), 6-13.

Wening, Sri. (2009). Workshop penulisan karya ilmiah sebagai upaya pengembangan profesionalisme guru SMK. Inoteks, 13(2), 171-181.

Yudi Yunika Putra, \& Adi Saputra. (2019). Workshop Publikasi Artikel Ilmiah dalam Jurnal Nasional Guru SMP Pangkalpinang. JPMB: Jurnal Pemberdayaan Masyarakat Berkarakter, 2(2), 207-215. 